This PDF is a selection from an out-of-print volume from the National Bureau of Economic Research

Volume Title: Behavioral and Distributional Effects of Environmental Policy

Volume Author/Editor: Carlo Carraro and Gilbert E. Metcalf, editors

Volume Publisher: University of Chicago Press

Volume ISBN: 0-226-09481-2

Volume URL: http://www.nber.org/books/carr01-1

Conference Date: June 11âf“"12, 1999

Publication Date: January 2001

Chapter Title: International Factor Movements, Environmental Policy, and Double Dividends

Chapter Author: Michael Rauscher

Chapter URL: http://www.nber.org/chapters/c10609

Chapter pages in book: (p. 187 - 216) 


\section{International Factor Movements, Environmental Policy, and Double Dividends}

Michael Rauscher

\subsection{The Issues}

The main purpose of environmental taxes is "to get the prices right." Emissions taxes signal the scarcity of environmental resources to their users and thus help to internalize negative environmental externalities. The idea dates back to Pigou (1920) and was taken up by modern environmental economics in the late 1960s; since that time environmental economists have tried to persuade politicians to introduce this incentive-compatible instrument as an efficiency-enhancing substitute of the still predominant command and control approach. Apparently, success has been limited. Environmental taxes are still the exception rather than the rule in environmental regulation. This has led economists to search for other arguments in favor of the introduction of environmental taxes. Are there additional dividends to be gained from an environmental tax reform? Such gains may exist, for green taxes generate tax revenues that may be used to alleviate other problems of the economic system. Two problem areas come to mind. The first one is the tax system, which in most countries is distortional. Green tax revenues may be used to reduce other taxes that distort the allocation of factors of production. The second problem area is the imperfection of the labor market, where union bargaining and efficiency wages result in a downward rigidity of real wages and cause unemployment.

Michael Rauscher is professor of international economics at Rostock University.

The author is indebted to David Bradford, Lans Bovenberg, Don Fullerton, conference participants, and participants of the Rostock Economics Research Seminar. The usual disclaimer applies. 
Thus, so the argument goes, green taxes can be used to alleviate the tax burden on labor and help to solve unemployment problems.

The efficiency of the tax system is a primary concern of the theory of public finance. The basic idea that green taxes may be used to create a more efficient tax system goes back to Tullock (1967). It has been reinforced by Pearce (1991) and Repetto (1992). Bovenberg and de Mooij (1994) challenge this view and show that the existence of other distortional taxes does not necessarily imply that green taxes should overinternalize environmental damages. On the contrary, it is more likely that an optimal environmental tax does not completely internalize the environmental damage. As Fullerton (1997) and Schöb (1997) show, this result decisively depends on the normalization of goods and taxes, and using other ways of normalizing one arrives at contradictory conclusions. For overviews summarizing the public finance aspects of the double dividend literature, see Goulder (1995, 1997). Fullerton and Metcalf (1998) extend the standard approach by allowing for rents that are appropriated by the private sector if the government chooses the command and control approach to environmental policy. In this case, less tax revenue is generated and the double dividend becomes even more unlikely.

In Europe, emphasis has been placed less on the efficiency of the tax system than on the reduction of unemployment. An early example is Binswanger et al. (1983). Recent contributions to this literature are Schneider (1997), Koskela, Schöb, and Sinn (1998), and Holmlund and Kolm (2000). The present paper looks at unemployment problems as well. I consider an open economy endowed with fixed quantities of labor and capital. Capital is mobile internationally, whereas labor is not. The environmental regulation uses the command and control approach, which generates rents that are appropriated by the private sector. This element of the model resembles the approach adopted by Fullerton and Metcalf (1998). However, in the present paper, this rent is linked to the mobile factor of production. This is an implicit subsidy, and it generates another distortion in the economy.

The paper is organized as follows. Section 6.2 presents the basic assumptions of the model. Then comparative static results will be derived and discussed. The next section is devoted to a revenue-neutral environmental tax reform. Afterward, I consider its welfare and employment effects. Then optimal environmental policies in first-best and second-best situations are discussed. Some final remarks conclude the paper.

\subsection{A Basic Model of Interjurisdictional Competition}

Consider a small open economy. It produces an aggregate good that can be used as an input and as a consumption good. There are one fixed and three variable factors of production. The fixed factor can be land and it is 
not considered explicitly in the model. Labor, $L$, is the immobile factor of production, which is tied to the jurisdiction under consideration. Labor supply is fixed at a level $L_{0}$. However, the wage rate is fixed as well, and I assume that there is unemployment. Capital, $K$, is the mobile factor of production and its domestic supply, $K_{0}$, is given and constant. The third factor of production is an environmental resource, $E$. Assume that $E$ is used up during the production process. For example, clean water enters the production process and contaminated water is discharged into the ambient. Thus, $E$, which measures the use of environmental resources, can also be interpreted as being a measure of emissions and contamination. Let the production function, $F(\cdot, \cdot, \cdot)$, exhibit diminishing returns to scale in the three variable factors of production. Thus, output, $Q$, is

$$
Q=F(L, K, E) \text {. }
$$

Let the production function have the usual properties, that is, positive first derivatives, negative second derivatives, positive second principal minors, and a negative determinant of the Hessian determinant. Moreover, we assume that

(2) $F_{K L} \equiv \frac{\partial^{2} F}{\partial K \partial L}>0, \quad F_{K E} \equiv \frac{\partial^{2} F}{\partial K \partial E}>0, \quad F_{L E} \equiv \frac{\partial^{2} F}{\partial L \partial E}>0$,

where the arguments of the production function have been omitted for convenience. This implies that the factors of production are technological substitutes. This kind of production function has become a standard tool for the modeling of international factor movements. See MacDougall (1960), Kemp (1964), and Ruffin (1984) for surveys. Applications to environmental policy can be found in Oates and Schwab (1988), Wang (1995), and Rauscher (1997, chap. 3). An example for such a production function is the Cobb-Douglas function,

$$
Q=L^{\alpha} K^{\beta} E^{\gamma} .
$$

Reasonable guesses for these parameters are $\alpha=0.6, \beta=0.3$, and $\gamma<0.1$.

Because there are three factors of production, there are three factor markets. Since there is only one good, there are no relative prices and the factors are remunerated in terms of this commodity. Assume that the demand sides of the markets are competitive. Then the factor is employed up to the point where its marginal productivity equals the factor price plus the rate of factor taxation.

The environmental resource market is governed by

$$
F_{E}=t^{E},
$$

where $t^{E}$ is the emissions tax rate measured in units of the aggregate good per unit of emissions. Note that this specification includes the possibility 
of a tradable-pollution-permits scheme or a command and control approach to environmental policy. In the case of a permits scheme, it is the market price of the right to discharge one unit of the pollutant. In the case of command and control, it is the implicit or shadow price of the environmental resource.

In the labor market, the net wage rate $w$ is exogenously given and larger than the market-clearing wage rate. Let $t^{L}$ be the labor income-tax rate. Labor demand is then determined by

$$
F_{L}=w\left(1+t^{L}\right) .
$$

Since the wage rate is fixed in this model, there may be unemployment. Of course, such an approach to modeling unemployment is simple-if not simplistic. A more realistic model would look at the process of wage bargaining between employers and the unions explicitly. In this case, the government would be in the strategic position to influence the game between the employers and the unions as a first mover. However, I wish to concentrate on the pure employment effects and to avoid complications stemming from solving multiple-stage games.

The capital market is also special in this model. There is an additional element of capital remuneration that is not present in the standard model of international factor movements. Consider a situation where command and control is the government's approach to environmental policy. Thus, firms are given the right to pollute up to an upper limit for free. In this case, the government has no environmental tax revenue, but the regulated private sector appropriates the rent, which is due to the scarcity of environmental resources. This rent equals the potential emissions tax revenue, $t^{E} E$. Who in the private sector is able to appropriate this rent? It is often assumed that it is redistributed to the factors of production in a lump-sum fashion. Then allocation would not be affected and market-based environmental policies and command and control would be equivalent. This approach is not followed here. Instead, we assume that the environmental scarcity rent accrues to those who employ capital as a factor of production. The underlying idea is that there is a kind of environmental regulation that fixes emissions per unit of investment. So, the right to pollute is tied to the capital stock. As an example, consider the case of electric power generation, where emissions are often linked to installed capacity, which in turn is closely related to the capital stock invested;' Wellisch (1995). Thus, for each unit of capital, a share $\left(t^{E} E\right) / K$ of this rent

1. An alternative way of justifying this approach is to extend the model to more than one good and to allow for international trade. If command and control is applied to the capitalintensive sector of the economy, then the owners of the enterprises that are active in this sector appropriate the resource scarcity rent. This has effects similar to an output subsidy. According to the Stolper-Samuelson theorem, the remuneration of the intensively used factor tends to rise. 
can be appropriated. To make this a bit more general, we will consider a situation where the government distributes a share $(1-s)$ of the emissions rights for free in a command and control framework and auctions $s$ in a market for tradable pollution permits. The parameter $s$ will be used for comparative statics in what follows. The market-clearing condition for the capital market is

$$
F_{K}+(1-s) \frac{t^{E} E}{K}=r\left(1+t^{K}\right)
$$

The net tax revenue of the government equals the sum of the revenues from all kinds of taxes minus the unemployment benefit. The unemployment benefit is determined by the benefit rate, $u$, and the level of unemployment, $L_{0}-L$, where $L_{0}$ is the exogenous supply of labor. We only consider situations where $L_{0}>L$. A wage rate lower than the equilibrium wage rate, where labor demand is constrained by labor supply, is ruled out.

$$
G=t^{L} w L+t^{K} r K+s t^{E} E-u\left(L_{0}-L\right) .
$$

In order to limit the number of possible scenarios in the remainder of the paper, I impose some additional assumptions. The first assumption is that the tax revenues from payroll taxes and from emissions taxes are both increasing in the tax rates. In other words, I consider situations to the left of the maximum of the Laffer curve:

$$
\frac{d\left(t^{L} w L\right)}{d t^{L}}>0, \quad \frac{d\left(t^{E} E\right)}{d t^{E}}>0 .
$$

This is the assumption underlying the unemployment version of the double dividend hypothesis as stated by Binswanger et al. (1983) and many others afterward. Green taxes generate additional tax revenue, and this tax revenue can be used to reduce labor taxes, which then leads to higher employment. The first part of this argument is probably correct. Currently, most emissions tax rates are so low that tax increases lead to less than proportional reductions in emissions and thus indeed generate additional tax revenue. This tax revenue can be used to reduce the tax revenue from labor taxes. Under the assumption made above, the reduction in tax revenue can be achieved by a reduction of labor taxes, which leads to less unemployment. If labor demand were very elastic, we would obtain increased tax revenues as a result of reduced labor taxes. This would be the third dividend of a green tax reform. However, tax revenue neutrality could only be achieved by higher taxes and less unemployment. I assume that this is not the case here.

The second assumption is made about the effect of changes in the capital stock on the environmental scarcity rent per unit of capital. Let this rent be denoted by $R$. Using equation (3a), we obtain 


$$
R=\frac{E F_{E}}{K},
$$

and

$$
R_{K}=\frac{E K F_{K E}-E F_{E}}{K^{2}}=\frac{R}{K}\left(\frac{K F_{K E}}{F_{E}}-1\right)<0 .
$$

$R_{K}$ consists of two components. On the one hand, the increase in the capital stock raises the marginal productivity of emissions and, thus, the scarcity rent. On the other hand, this rent is distributed to a larger capital stock such that the rent per unit of capital is reduced. I assume that the second effect dominates the first. This assumption is satisfied in the case of a Cobb-Douglas production function since the elasticity, which is the first term in brackets on the right-hand side, is always less than one. This concludes the exposition of the model.

\subsection{Comparative Statics}

What are the effects of changes in environmental and tax policies on the employment of labor and on the capital stock in the economy? We eliminate $t^{E}$ and rewrite equation (3c) such that we obtain the following system of factor market equations:

$$
\begin{gathered}
F_{L}=w\left(1+t^{L}\right), \\
F_{K}+(1-s) \frac{F_{E} E}{K}=r\left(1+t^{K}\right) .
\end{gathered}
$$

Total differentiation yields

$$
\begin{aligned}
& \left(\begin{array}{cc}
F_{L L} & \multicolumn{1}{c}{F_{L K}} \\
F_{L K}+(1-s) R_{L} & F_{K K}+(1-s) R_{K}
\end{array}\right)\left(\begin{array}{l}
d L \\
d K
\end{array}\right) \\
& =\left(\begin{array}{cccc}
w & 0 & -F_{L E} & 0 \\
0 & r & -F_{K E}-(1-s) R_{E} & R
\end{array}\right)\left(\begin{array}{c}
d t^{L} \\
d t^{K} \\
d E \\
d s
\end{array}\right) .
\end{aligned}
$$

The sign of the determinant of the matrix on the left-hand side is ambiguous. This is due to the term $(1-s) R_{L}$ in the second-row first-column element of the matrix. All other terms in this matrix are such that the determinant is positive. In the case of a Cobb-Douglas function, these effects dominate and the determinant turns out to be

$$
\Delta=(1-\alpha-\beta)[\alpha \beta+(1-s) \alpha \gamma] \frac{Q^{2}}{K^{2} L^{2}}>0 .
$$


Assume that this can be generalized. Then the following comparative static results can be derived:

- An increase in the payroll tax leads to less employment, since the gross wage that has to be paid by the employers is raised. This reduction in labor demand reduces the marginal productivity of capital. Capital leaves the country.

- An increase in the tax on mobile capital induces capital flight. With less capital, the marginal productivity is smaller and labor demand is reduced. Thus, unemployment is increased.

- The same effect shows up if $s$ is increased, that is, if there is a move from command and control toward incentives in environmental policy. The reason is that the share of the resource rent going to the mobile factor of production is reduced. This means that the implicit subsidization of the employment of the mobile factor is diminished. A reduction of a subsidy must have the same effect as the increase of a factor tax.

- The effects of an emissions reduction (i.e., a tighter environmental policy) are ambiguous. There are two components of the effect. The first is the standard effect that is expected from stricter environmental standards: Employment is reduced and capital is driven out of the country, since the productivities of the other factors of production are reduced. Here, however, there is also a second effect. A tighter environmental policy implies a higher (implicit) environmental tax rate. Due to the Laffer-curve assumption, this has the effect that the (implicit) tax revenue (i.e., the environmental scarcity rent) is increased. Thus, the implicit subsidy going to capital is increased. Thus, demand for capital rises, and the marginal productivity of labor is increased. Employment rises.

\subsection{A Tax-Revenue-Neutral Environmental Policy Reform}

Let us consider an environmental policy reform that keeps the tax revenue constant. What do I mean by tax revenue neutrality here? Formally, tax revenue neutrality is defined as a constant level of $G$ even though some tax rates are changed. Note that $G$ is not the total tax revenue but the tax revenue minus unemployment benefits. So, the government aims at having a constant budget after the unemployment benefits have been paid. In what follows, it is assumed that the government uses $G$ to provide public consumption goods. Tighter environmental standards lead to an increased emissions tax revenue and the additional revenue can be used to reduce distortional labor taxes. However, one should note that there are also some indirect effects on the tax revenue since environmental policies have an impact on factor demand and, thus, on other components of the tax revenue as well. This will be discussed later. 
Another issue must be mentioned as well. In a recent paper, Kaplow (1996) emphasizes that income taxes can be used as a source of financing public goods without the generation of distortions. Applied to environmental taxation and green tax reforms, this implies that income (labor) taxation schemes are possible such that the optimal environmental tax is the Pigouvian tax, which equals marginal environmental damages. However, in this model, matters are different (as will soon be seen) since, first, the labor supply is fixed and, therefore, changes in labor taxes have no impact on the factor allocation via the supply side of the labor market; and, second, there are other distortions in this model that imply modifications of the Pigouvian rule for emissions tax rates.

The following changes in environmental policy are considered: (1) a move from command and control toward environmental taxes or tradable pollution permits; (2) a tighter environmental policy, that is, a reduction in total emissions; and (3) a combination of these instruments such that $s E$ remains unchanged, that is, the stricter environmental policy is achieved by reducing the number of pollution permits that are given out for free, whereas the number of pollution permits auctioned by the governments remains unchanged. Two objectives will be considered: the reduction of unemployment and the increase of social welfare.

First consider the employment objective. A move from command and control has direct and indirect effects on the demand for labor. The direct effect is a reduction in labor demand, since labor productivity falls as a consequence of tighter environmental standards. There are three types of effects on tax revenue. There is a direct effect: A move from command and control toward pollution permits generates additional tax revenue. There are three first-order indirect effects. The first affects the tax revenue from capital taxation; since capital leaves the country when its indirect subsidization is reduced, the capital tax revenue is reduced. Second, if capital leaves the country, labor productivity declines, employment shrinks, and the revenue from payroll taxes is reduced. Third, due to the unemployment benefits that the government has to pay out of its budget, if employment is reduced, this exerts an additional pressure on the government budget. ${ }^{2}$ Finally, there are second-order indirect effects. If employment and capital are reduced, then the marginal productivity of emissions declines. There is less demand for environmental resources and the emissions tax revenue is reduced.

The direct effect and the indirect effects can be compared easily. In order to do this, the tax revenue is differentiated with respect to $s$. This yields

2. In the case of an earmarked tax on labor, an instrument that is used in several countries to finance unemployment benefits, the tax rate must increase since fewer employees have to finance more of the unemployed. This generates additional costs of employing people and additional workers tend to be dismissed. 
(9) $\frac{d G}{d s}=F_{E} E+\left[t^{K} r \frac{d K}{d s}+\left(t^{L}+u\right) w \frac{d L}{d s}\right]+s E\left[F_{K E} \frac{d K}{d s}+F_{L E} \frac{d L}{d s}\right]$,

where $d K / d s$ and $d L / d s$ follow from equation (8). The first term in brackets on the right-hand side contains the first-order indirect effect. It can be seen that the negative effects dominate if the tax rates are large in the initial situation. This is not particularly surprising. If the tax rates are large, then the impact of a decline in factor demand on the tax revenue is substantial. The second term in brackets contains the second-order indirect effects on the emissions tax revenue.

In a second step, consider a reduction in emissions at a constant level of $s$. The ratio of pollution permits allocated by command and control to the permits allocated via markets stays constant. The total effect on tax revenue is not clear. Again, this can be decomposed into direct and indirect effects. The direct effect of the tighter environmental policy is an increase in the tax revenue due to the assumption that the economy is on the upward-sloping part of the Laffer curve. There are two possible first-order indirect effects. On the one hand, tighter environmental policies reduce the productivities of the other factors; this implies declining factor demands and declining tax revenues. On the other hand, the increase in the tax revenue is equivalent to an increase in the scarcity rent and, therefore, in the hidden subsidy; this implies increasing factor demands and increasing tax revenues. The second-order indirect effects amplify the first-order effects. If unemployment increases and capital leaves the country, then the negative effect on the tax revenue is aggravated by the decline in the emissions tax rate.

Algebraically, we obtain

$$
\begin{aligned}
\frac{d G}{d E}= & s \frac{\left(F_{E} E\right)}{d E}+\left[t^{K} r \frac{d K}{d E}+\left(t^{L}+u\right) w \frac{d L}{d E}\right] \\
& +s E\left[F_{K E} \frac{d K}{d E}-F_{L E} \frac{d L}{d E}\right] .
\end{aligned}
$$

The importance of the first-order indirect effects again depends on the initial tax rates as in the case of a movement from command and control toward market instruments.

An interesting side issue should be mentioned. Even if there is pure command and control regulation, tighter environmental policies may have positive effects on tax revenues. If the resource-rent effect of the strict policy dominates, it is possible that capital moves into the country, that as a consequence employment rises, and that, therefore, the tax base is expanded. Thus, it becomes possible to reduce labor taxes and increase employment even further. 
The combination of a reduction in emissions and an increase in $s$ yields ambiguous results again. The direct effect on the tax revenue is positive since the scarcity of the environmental resource is increased and, thus, so is the emissions tax revenue. Moreover, the move from command and control to market-oriented environmental policy makes producers pay taxes for a larger share of their emissions. The first-order indirect effects are ambiguous again, but they are less likely to be positive than in the case of a mere tightening of environmental regulation since the impact of the increase in $s$ is unambiguously negative. The second-order indirect effects depend on the first-order effects and reinforce them.

The ambiguity of the results of this model has obvious and intuitive explanations. Unfortunately, despite its simplicity the model is already so complex that it is difficult to come up with interpretable algebraic conditions for the positive and negative effects of environmental tax reform. Comparing the results to those derived from closed-economy models, however, one can make the following statements. (1) In a standard model of an open economy without indirect subsidization of the mobile factor, a double dividend from tighter environmental policy or from the introduction of market instruments is less likely than in a closed economy. Because these policy measures induce capital flight, this reduces the tax base and the tax revenue. Moreover, there are repercussions on the labor market that increase unemployment. Finally, second-order effects on the emissions tax revenue must be taken into account and they amplify the first-order indirect effects. (2) If this model is extended by the introduction of an environmental scarcity rent associated with the mobile factor, these negative effects are mitigated or even reversed.

Now consider welfare effects of the environmental policy reform. For simplicity, I assume a social-welfare function that is quasi-linear and additively separable in its arguments. This causes no loss of generality here, since I am not interested in doing comparative statics with respect to welfare maxima, but just looking at welfare effects and, later on, at optima. For this purpose, interaction terms of different arguments of the utility function do not provide additional insights.

Let the welfare function be defined as

$$
W=Y+v(G)-d(E),
$$

where $Y$ denotes consumable income, $v(\cdot)$ is an increasing and strictly concave utility function evaluating the benefits accruing to the residents of the jurisdiction from the consumption of the public good supplied by the government, and $d(\cdot)$ is an increasing and convex function measuring the environmental damage. The net government revenue available for the generation of the public consumption good was defined in equation (4) as

$$
G=t^{L} w L+t^{K} r K+s t^{E} E-u\left(L_{0}-L\right),
$$


and the consumable income is output minus interest payments to foreigners minus the tax revenue needed for the generation of the public consumption good:

$$
Y=f(K, L, E)-r\left(K-K_{0}\right)-G .
$$

Here the implicit assumption is that all residents have utility functions that are linear in income and that the total utility derived from income is the sum of all individual utilities. This implies, for instance, that the unemployed, who have lower incomes than those who have jobs, have the same marginal utility as the employed people.

Now consider a tax-revenue-neutral environmental policy reform. Revenue neutrality implies that the change in environmental policy is accompanied by a change in labor taxation such that the net tax revenue available for the provision of public goods remains unchanged. This change in labor taxation may be achieved by a change in general payroll taxes. The corrections that are necessary to achieve revenue neutrality have the same effects on the allocation of labor and capital. Algebraically, this follows from equations (8) and (11). The economic intuition is that tax money is fungible, and if the tax base is the same in both cases, then the allocation effects must be the same as well.

Let us now denote by $(d K / d s)$ the total capital-stock effects and by $(d L /$ $d s$ ) the labor-employment effects of the environmental tax reform taking the shape of a move away from command and control. That is, these terms include the adjustments that are necessary to achieve the balanced budget. ${ }^{3}$ The welfare effect is

$$
\frac{d W}{d s}=\left[t^{K}-(1-s) R\right] \frac{d K}{d s}+F_{L} \frac{d L}{d s} .
$$

There are two components. The first one is due to the induced change in the capital stock. If the capital stock is increased, this is positive for the economy if the tax rate is larger than the rate of subsidization, that is, if capital is a tax base and if some additional tax revenue can be generated from attracting foreign capital. If the capital tax rate is low and the environmental resource rent is large, this effect may be turned around. It is beneficial to lose a factor that is subsidized. But under which circumstance does the country lose this factor? One effect of the environmental policy reform is that capital leaves the country because the implicit subsidy is reduced. However, if the reform generates enough additional tax revenue such that the labor tax rate can be reduced, employment rises and this helps the jurisdiction to attract foreign capital. Increasing the labor force is always positive from a welfare point of view. Unemployed labor is idle

3. Note that this implies that $d K / d s$ and $d L / d s$ differ from the values that follow from the simple comparative statics of equation (8). 
and does not contribute to the general well-being. So, the marginal gain from increasing the employment by one unit is the marginal productivity of labor. ${ }^{4}$

Similar considerations apply if the environmental policy reform consists of an emissions reduction. The welfare effect is

$$
\frac{d W}{d E}=\left[t^{K}-(1-s) R\right] \frac{d K}{d E}+F_{L} \frac{d L}{d E}+F_{E}-d^{\prime} .
$$

The interpretation of the first two terms corresponds to that of the previous case. There is a tax-base effect for capital and a benefit from reduced unemployment. The last two terms on the right-hand side of equation (14) denote the main dividend of environmental policy. They measure the difference between the marginal benefit of emissions (more output) and their marginal damage (environmental disruption). If the environmental policy is lax in the initial situation, then there is a substantial reduction in environmental damage and a relatively small reduction in output: Stricter environmental standards have a positive welfare effect. If the environmental policy is relatively strict already, then this term denotes a negative welfare effect of even tighter environmental policy.

In the case of a policy reform that combines a reduction in emissions with a move from command and control, the welfare effect is straightforward. Note that $d s / d E=s / E$ if $s E$ is constant. This implies

$$
\begin{aligned}
\left.\frac{d w}{d E}\right|_{s E=\mathrm{const}}= & {\left[t^{K}-(1-s) R\right]\left(\frac{d K}{d E}-\frac{s}{E} \frac{d K}{d s}\right)+F_{L}\left(\frac{d L}{d E}-\frac{s}{E} \frac{d L}{d s}\right) } \\
& +\left(F_{E}-d^{\prime}\right) .
\end{aligned}
$$

Again, there are three effects: a tax-base effect, a labor-market effect, and the environmental dividend. The reduction in emissions and the increase in $s$ may have opposing effects on capital and labor.

\subsection{Optimal Taxation and Interjurisdictional Competition}

Having derived the effects of a revenue-neutral tax reform, we can now proceed by asking the normative question of what an environmental policy should look like. This will be done in a first step for the first-best situation, when there are no restrictions on the policymaker's choice set; all tax instruments are available. Afterward, I consider restrictions on the choice set and second-best taxation. Also, issues of interjurisdictional competition are addressed. As in other tax competition models, we employ the

4. Note that this term vanishes if there is no unemployment. Algebraically, this can be seen if a nonnegativity constraint for the upper limit to employment is introduced. The corresponding Kuhn-Tucker multiplier is 0 in the case of unemployment and jumps to a positive value if labor demand hits labor supply. 
helpful assumption that the jurisdictions are identical. This is done by Zodrow and Mieszkowski (1986) for a simple tax-competition model and by Rauscher (1999) for a variety of tax-competition models involving environmental taxes and different kinds of factor- and goods-market distortions. The advantage of the identity assumption is that situations with and without tax competition can be compared easily since the mobile factor does not move ex post. Ex ante, however, each jurisdiction has an incentive to influence the location of the mobile factor. This leads to fiscal and other externalities and to suboptimal taxation.

I will start with the first-best situation. All kinds of taxes are available to the policymaker including a lump-sum tax, $\Theta$. Taking all restrictions into consideration, a benevolent policymaker maximizes

$$
W=f(K, L, E)-r\left(K-K_{0}\right)-G+v(G)-d(E),
$$

subject to

$$
\begin{gathered}
G=\Theta+t^{L} w L+t^{K} r K+s t^{E} E-u\left(L_{0}-L\right), \\
L_{0}-L \geq 0 .
\end{gathered}
$$

Maximization with respect to the lump-sum tax rate yields the result that the marginal utility of the public good in the optimum equals unity. This is explained by the fact that the marginal cost of providing it is one unit of the aggregate good. Moreover, we have the optimal tax rates and other policy parameters:

$$
\begin{gathered}
t^{K}=(1-s) R, \\
t^{E}=d^{\prime}, \\
t^{L}=F_{L}\left(K, L_{0}, E\right)-w .
\end{gathered}
$$

The mobile factor should neither be taxed nor subsidized. Thus a combination of the capital tax rate and the command and control parameter must be chosen such that their impacts on the capital market just cancel out. This result corresponds to the well-known zero-taxation property in the international tax competition literature. The environmental tax rate equals the environmental damage. The labor tax rate is negative: labor is subsidized to the point where the labor demand equals the total labor force. Since there is no unemployment, the allocation is not affected by the design of the unemployment compensation. From the point of view of the environmental economist, it is important to note that the emissions tax rate equals the Pigouvian tax rate. There is no underinternalization of environmental externalities. The reason is the availability of an efficient tax instrument, the lump-sum tax. This is used to finance the public good, and the other taxes just correct the market failures in the markets for the environmental resource and for labor. 
Let us now consider a second-best world, where lump-sum taxes are not available. In order to simplify the analysis a bit, I take into account the fact that capital taxes and the command and control parameter are perfect substitutes. Thus, I optimize with respect to the labor, capital, and emissions tax rates only. The system of first-order conditions is

$$
\begin{gathered}
\left(F_{K}-r\right) \frac{d K}{d t^{K}}+\left(F_{L}-\lambda\right) \frac{d L}{d t^{K}}=\left(1-v^{\prime}\right) \frac{d G}{d t^{K}}, \\
\left(F_{K}-r\right) \frac{d K}{d t^{L}}+\left(F_{L}-\lambda\right) \frac{d L}{d t^{L}}=\left(1-v^{\prime}\right) \frac{d G}{d t^{L}}, \\
\left(F_{K}-r\right) \frac{d K}{d E}+\left(F_{L}-\lambda\right) \frac{d L}{d E}=\left(1-v^{\prime}\right) \frac{d G}{d E}-\left(F_{E}-v^{\prime}\right),
\end{gathered}
$$

where $\lambda$ is the Kuhn-Tucker multiplier associated with the condition that employment cannot exceed the labor force. This can be rewritten in matrix form:

$$
\left(\begin{array}{lll}
\frac{d K}{d t^{K}} & \frac{d L}{d t^{K}} & 0 \\
\frac{d K}{d t^{L}} & \frac{d L}{d t^{L}} & 0 \\
\frac{d K}{d E} & \frac{d L}{d E} & 1
\end{array}\right)\left(\begin{array}{l}
F_{K}-r \\
F_{L}-\lambda \\
F_{E}-d^{\prime}
\end{array}\right)=\left(\begin{array}{l}
\left(1-v^{\prime}\right) \frac{d G}{d t^{K}} \\
\left(1-v^{\prime}\right) \frac{d G}{d t^{L}} \\
\left(1-v^{\prime}\right) \frac{d G}{d E}
\end{array}\right)
$$

Substituting from equation (10) for $d G / d E$ on the right-hand side of this equation and using similar results for the partial derivatives of $G$ with respect to the labor and capital taxes, we have

$$
\begin{aligned}
\left(\begin{array}{lll}
\frac{d K}{d t^{K}} & \frac{d L}{d t^{K}} & 0 \\
\frac{d K}{d t^{L}} & \frac{d L}{d t^{L}} & 0 \\
\frac{d K}{d E} & \frac{d L}{d E} & 1
\end{array}\right)\left(\begin{array}{c}
F_{K}-r-\left(1-v^{\prime}\right)\left(t^{K} r+s E F_{K E}\right) \\
F_{L}-\lambda-\left(1-v^{\prime}\right)\left[\left(t^{L}+u\right) w+s E F_{L E}\right] \\
F_{E}-d^{\prime}
\end{array}\right) \\
=\left(\begin{array}{c}
\left(1-v^{\prime}\right) r K \\
\left(1-v^{\prime}\right) w L \\
\left(1-v^{\prime}\right) \frac{d\left(s E F_{E}\right)}{d E}
\end{array}\right)
\end{aligned}
$$

For the case of constant returns to scale, full employment, and flexible wages, it has been shown by Lorz, Scholz, and Stähler (1999) that this system has the simple solution that environmental taxes are Pigouvian, capital taxes are 0 , and the whole tax burden resulting from the necessity 
to provide the public good falls on labor. Formally the reason for this result is the constant-returns-to-scale assumption. Constant returns to scale imply that the factor-price frontier does not depend on output. That is, if two marginal factor productivities are given, the third one is determined. In the case of flexible wages, the labor tax leaves the gross wage (including the tax rate) that the producer has to pay unchanged and the whole tax burden is borne by the factor that is available in fixed supply. This is a kind of lump-sum result.

In the case of unemployment, matters are different. Higher labor taxes lead to less employment and higher unemployment benefits. Thus, it is not clear whether the state has to use taxes on other inputs to finance the supply of public goods. Assume for instance that the optimal supply of public goods is achieved, that is, $v^{\prime}=1$. Since the matrix on the left-hand side of equation (22) has full rank, it follows that $F_{K}=r$ and $F_{E}=d^{\prime}$. The capital tax rate should be 0 and the emissions tax rate should equal marginal environmental damage. If there is unemployment, then the shadow price $\lambda$ is 0 . But this has the consequence that the marginal productivity of labor is 0 . This is an obvious contradiction to the unemployment assumption that was just made. If there is full employment, the shadow price is positive, and a subsidy has to be paid to the employers to make them hire people whose marginal productivity is below the wage rate. This is in almost all imaginable cases incompatible with the tax revenue being generated by green taxes. Due to the complexity of the model, explicit optimal solutions can be computed only for calibrated versions of this model.

Similar considerations apply if we look at an optimal environmental tax reform where capital taxes are given. This makes matters simpler since there are only two first-order conditions, equations (22b) and (22c). Moreover, it is assumed that the government uses this possibility to reconsider its budget. Thus, the budget is flexible as well.

Now we discuss environmental tax reform where the government considers the possibilities of using tax revenues to reduce labor taxes and, thus, unemployment or to improve the supply of public goods. Two cases are imaginable. Let us start from a situation where there is Pigouvian taxation of emissions, zero taxation of labor, and a large demand for public goods. A marginal change in environmental regulation has an effect on the environment and on output that cancel out in the case of Pigouvian taxes. In the first case, emissions taxes generate additional tax revenue; then this tax revenue is used to reduce labor taxes or even to subsidize labor and to improve the supply of public goods. The tax rate tends to be higher than the Pigouvian tax rate. If higher environmental taxes happen to reduce total tax revenue (via their impact on the demand for the other factors), it is better to use lax environmental regulation to create more employment and to produce additional public goods. Then the emissions tax rate should be lower than the Pigouvian rate. 
Finally consider the second-worst case, where the government has the environmental tax as its only policy instrument. Optimization of the welfare function with respect to emissions, $E$, yields the first-order condition

$$
\left(F_{K}-r\right) \frac{d K}{d E}+\left(F_{L}-\lambda\right) \frac{d L}{d E}=\left(1-v^{\prime}\right) \frac{d G}{d E}-\left(F_{E}-v^{\prime}\right),
$$

which can be rearranged to

$$
t^{E}=v^{\prime}+\left(F_{K}-r\right) \frac{d K}{d E}+\left(F_{L}-\lambda\right) \frac{d L}{d E}+\left(v^{\prime}-1\right) \frac{d G}{d E} .
$$

The emissions tax consists of four components, one for each distortion in the economy:

1. Environmental externality: The larger marginal environmental damage, the larger is the (implicit) emissions tax.

2. Taxation of the mobile factor of production: If the tax dominates, the term in parentheses is positive; if the indirect subsidy is larger, then it is negative. The sign of $d K / d E$ is indeterminate. So, if tighter environmental standards attract capital, we should use them if the capital is a tax base; and we should employ lax standards if capital is subsidized. The opposite conclusions should be drawn if tighter standards imply capital flight.

3. Labor market distortion: The tax rate should be adjusted to reduce unemployment. Depending on the sign of $d L / d E$, this can be achieved either by relatively lax or relatively tight environmental standards.

4. Absence of a lump-sum tax for financing the provision of the public good: If the public good is scarce, $v^{\prime}>1$, then the environmental policy should be designed such that it generates additional tax revenue. If the consumption good is scarce, then the environmental tax should be low such that consumption is raised at the expense of the supply of public good.

If in an interjurisdictional competition many jurisdictions interact, they all use the biased environmental policies, but they never manage to attract additional capital nor are they able to repel capital in the case of indirect subsidization through command and control. The outcome, thus, is an unfavorable tax competition, where everybody uses taxes that are either too high or too low without achieving their objectives. As in the tax competition and fiscal federalism literatures, there is a prisoner's dilemma that can only be solved by international policy coordination.

\subsection{Summary and Conclusion}

This paper has addressed environmental policy in a distorted small open economy. It is shown that the fact that the scarcity rent of the resource, which goes to the private sector in the case of command and control, is 
linked to capital has a number of interesting consequences. It may happen that tighter environmental standards attract rather than repel mobile capital from the jurisdiction imposing these standards. Whether or not this is relevant in practice is an empirical question. Given the specification of the model, it should be possible to determine the relevant parameters and to calculate some crude estimates for the comparative statics terms.

Another interesting result of this paper is that a move from command and control to more market-oriented environmental policies may do the economy some harm, since it can induce environmental capital flight if environmental scarcity rents are linked to the mobile factor of production.

One should expect, however, that all these effects are rather small. Environmental regulation has only a minor impact on the cost side of the manufacturing industry. This may explain the limited and often anecdotal, rather than statistically significant, evidence of capital relocation as a consequence of tighter environmental standards. Some authors argue that this lack of evidence may be due to methodological problems (e.g., Folmer and Jeppesen 1999); nonetheless, in most cases, only drastic changes in environmental policies will induce significant relocation. So, in spite of the fact that this paper seems to imply some deviations from standard environmental-policy recommendations, the simple rule that the emissions tax rate should equal marginal damage is still a good rule of the thumb. After 30 years of theoretical environmental economics, the main problem in practice is still to internalize externalities and to get the prices right.

\section{References}

Binswanger, H. C., H. Frisch, H. G. Nutzinger, B. Schefold, G. Scherhorn, U. E. Simonis, and B. Strümpel. 1983. Arbeit ohne Umweltzerstörung: Strategien einer neuen Wirtschaftspolitik. Frankfurt am Main: Fischer.

Bovenberg, A. L., and R. de Mooij. 1994. Environmental levies and distortionary taxation. American Economic Review 84:1085-89.

Folmer, H., and T. Jeppesen. 1999. Environmental policy and location behavior of firms: A synopsis of the micro and regional science literature. European Studies Discussion Paper no. 34. Odense: Syddansk Universitet.

Fullerton, D. 1997. Environmental levies and distortionary taxation: Comment. American Economic Review 87:245-51.

Fullerton, D., and G. E. Metcalf. 1998. Environmental controls, scarcity rents, and pre-existing distortions. University of Texas at Austin. Working paper.

Goulder, L. H. 1995. Environmental taxation and the "double dividend": A reader's guide. International Tax and Public Finance 2:157-83.

1997. Environmental taxation in a second-best world. In International yearbook of environmental economics 1997/1998, ed. H. Folmer, and T. Tietenberg 28-54. Cheltenham, U.K.: Elgar.

Holmlund, B., and A. -S. Kolm. 2000. Environmental tax reform in a small open economy with structural unemployment. International Tax and Public Finance, 7 (3): 315-33. 
Kaplow, L. 1996. The optimal supply of public goods and the distortionary cost of taxation. National Tax Journal 49:513-33.

Kemp, M. C. 1964. The pure theory of international trade. Englewood Cliffs, N.J.: Prentice Hall.

Koskela, E., R. Schöb, and H. -W. Sinn. 1998. Pollution, factor taxation and unemployment. International Tax and Public Finance 5:379-96.

Lorz, O., C. M. Scholz, and F. Stähler. 1999. Environmental taxes, public goods, and capital mobility. Institute of World Economics, Kiel. Mimeo.

MacDougall, G. D. A. 1960. The benefits and costs of investment from abroad, a theoretical approach. Economic Record 36:13-35.

Oates, W. E., and R. M. Schwab. 1988. Economic competition among jurisdictions: Efficiency enhancing or distortion inducing? Journal of Public Economics 35:333-54.

Pearce, D. 1991. The role of carbon taxes in adjusting to global warming. Economic Journal 101:938-48.

Pigou, A. C. 1920. The economics of welfare. New York: Macmillan.

Rauscher, M. 1997. International trade, factor movements and the environment. Oxford: Oxford University Press.

- 1999. Interjurisdictional competition and environmental policy. In International yearbook of environmental economics, ed. H. Folmer and T. Tietenberg. Cheltenham, U.K.: Elgar, forthcoming.

Repetto, R. 1992. Green fees: How a tax shift can work for the environment and the economy. Washington, D.C.: World Resources Institute.

Ruffin, R. J. 1984. International factor movements. In Handbook of international economics, vol. 1, ed. R. W. Jones and P. B. Kenen, 237-88. Amsterdam: North-Holland.

Schneider, K. 1997. Involuntary unemployment and environmental policy: The double dividend hypothesis. Scandinavian Journal of Economics 99:45-59.

Schöb, R. 1997. Environmental taxation and pre-existing distortions: The normalization gap. International Tax and Public Finance 4:167-76.

Sinn, H. -W. 1994. How much Europe? Subsidiarity, centralization and fiscal competition. Scottish Journal of Political Economy 41:85-107.

Tullock, G. 1967. Excess benefit. Water Resources Research 3:643-44.

Wang, L. -J. 1995. Environmental capital flight and pollution tax. Environmental and Resource Economics 4:273-86.

Wellisch, D. 1995. Locational choice of firms and decentralized environmental policy with various instruments. Journal of Urban Economics 37:290-310.

Zodrow, G. R., and P. M. Mieszkowski. 1986. Pigou, Tiebout, property taxation, and the underprovision of public goods. Journal of Urban Economics 19:356-70.

\section{Comment David F. Bradford}

Michael Rauscher's paper on the impact of alternative fiscal and environmental rules on the level of unemployment raises modeling and practical policy issues of general interest. These comments address three of them:

David F. Bradford is professor of economics and public affairs at Princeton University, adjunct professor of law at New York University, and a research associate of the National Bureau of Economic Research. 
- The adequacy of the rigid-wage view of labor-market equilibrium as the basis for modeling the impact of policy, environmental or otherwise, on unemployment.

- The incentive impact of typical methods of regulating emissions, operating through rent creation.

- The consequences of modeling distributive instruments more explicitly.

With support from the literature, Rauscher sets the problem in a small open economy with an economic "imperfection" in the form of a fixed wage rate. The fixed wage rate is treated as the culprit in explaining an excess supply of labor (i.e., unemployment) in equilibrium. His paper investigates the consequences of various policies - including, importantly, environmental policies - on unemployment. In addition to the fixed wage, the model adduces two other instances of rigidity, in this case rigidity of regulatory and fiscal rules. The first is a requirement that a tax on labor be set to finance a particular fraction of unemployment benefits. The second is a requirement that the revenue from a tax on emissions be used to finance a subsidy to the employment of capital. Unlike the wage rigidity, variation in these fiscal rigidities is treated as available to policymakers or, at least, admissible as open to investigators.

Another fiscal rigidity lurks in the background. That is the infeasibility of lump-sum taxes, an assumption that is standard in second-best tax analysis. As has been emphasized by, for example, Stiglitz (1982), however, it is hard to motivate the nonavailability of lump-sum taxes without taking into account distributional concerns. Introducing and modeling distribution explicitly (e.g., endowing people with different labor productivities) can rather dramatically change second-best conclusions of the sort developed in the present paper.

\section{Modeling Unemployment Equilibrium}

Rauscher's model has a single uniform output (the good) and three uniform factors of production - labor, capital, and emissions - all treated as flows, and a further factor (perhaps land), described as fixed. The good is taken as numeraire and is treated as untaxed throughout. Suppliers of labor receive $w$ per unit (which might be per hour or per year); suppliers of capital receive $r$ per unit, and we can think of suppliers of emissions as receiving 0 per unit. Unless we are thinking about the productive sector of the economy as a single firm, it might be preferable to speak of the fourth factor as offered in perfectly inelastic supply, rather than as fixed (to particular firms). (In fact, I don't think it would change anything if the fourth factor were supplied with a general supply function.) The price of the fourth factor is not specifically discussed in the model. In order for the 
system to work, however, presumably the fourth factor is priced, let us say at $p^{L}$.

Purchasers of the four factors, the firms, pay these amounts gross of any taxes and net of any subsidies. The tax on emissions may take the form of an explicit price of allowances, $t^{E}$, or it may be implicit in a regulatory constraint. The firms are treated as price takers in all markets and they all operate with the same constant-returns-to-scale production function.

The wage, $w$, is treated as fixed by some political process in the background. The price of capital services, $r$, is fixed in the big world capital market. The price of emissions is set by policy. The price of land is set by market clearing. Once any other tax/subsidy rates have been specified (perhaps determined as a feature of equilibrium), the cost of factor inputs to the firms is determined. This means the factor proportions are determined. The scale of output is determined by the land market-clearing condition and this determines all the other factor demands in equilibrium. It is assumed that the demand for labor falls short of the supply, so that there is unemployment in equilibrium.

Having laid out this model, Rauscher shows us how variations in policies not specifically related to the labor market may, indirectly, perturb the equilibrium in the direction of greater employment. Specifically, a subsidy to the employment of capital, which might be indirectly implemented through environmental regulation, might have this effect.

As noted by Rauscher, a rigid-wage model along the lines described has been fairly widely employed in the European literature. Exercising the discussant's privilege to offer more or less unsupported opinion, I would express the view that, even if the politically fixed wage model were well supported empirically, adopting rather subtle combinations of policies apparently unrelated to the labor market seems to me a rather peculiar approach to the unemployment problem. If the policymakers cannot understand what the model takes for granted as obvious, will they be persuaded by much more sophisticated modeling features (and by conclusions that are contingent on parameter values as well as specification)?

I am also unconvinced of the empirical adequacy of the rigid-wage model. Here I am stepping even more over the bounds of areas of economics in which I can claim any expertise. But, again in the spirit of stimulating discussion, I offer my version of a minimum wage equilibrium as having perhaps some advantages, particularly in drawing attention to the distributive aspects of the policy problem.

\section{An Alternative Specification}

My suggestion is to deploy the model used in optimal income-tax analysis. Instead of assuming that workers are perfect substitutes, suppose they differ in their abilities to provide labor services. Specifically, assume that a worker of type (skill level) $q$ who works for 1 unit of time provides $q$ 


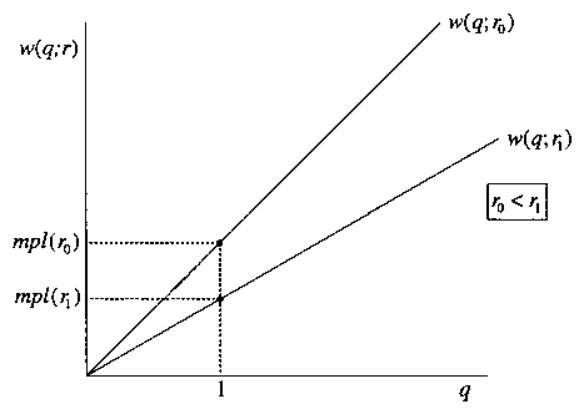

Fig. 6C.1 Two skill-premium schedules

units of standardized labor services. The value of a unit of standardized labor services in production will be denoted $\mathrm{mpl}$, that is, the usual marginal product of labor.

Consider a two-factor version of the story. Under standard competitive conditions, firms will want to hire any worker whose hourly wage is equal to or less than the product of the worker's skill and $\mathrm{mpl}$. (I am here assuming a worker's $q$ is public knowledge.) Under competition for workers there will be an equilibrium skill-premium structure, which we may denote $w(q)$, relating the worker's skill level to the hourly wage received. Here the relationship is given by equation (1).

$$
w(q)=q \cdot m p l .
$$

Any worker of type $q$ willing to work for $w(q)$ will be employed.

With variable capital, firms will be willing to pay more for workers, the lower the going rental rate. So the marginal product of standardized labor in equilibrium will be a function $\operatorname{mpl}(r)$ of the rental rate of capital. There will then be a skill premium structure, equation (2), that depends on the rental rate,

$$
w(q ; r)=q \cdot \operatorname{mpl}(r) .
$$

Figure 6C.1 illustrates this.

A possible model of unemployment caused by wage rigidity is now available. If the rigidity takes the form of a minimum wage per unit time, independent of skill, there would be a cutoff level of worker skill below which workers could not be legally employed. Since competitive firms will not pay a worker more than his or her marginal product, workers with subcritical skill levels will be unemployed. The extent of unemployment will be determined by the proportion of such workers in the labor force. With lower interest rate, ceteris paribus, more capital will be employed and the cutoff skill level will be lower, as illustrated in figure 6C.2, where $\bar{w}$ is the minimum wage allowed per unit of worker time. (Variations on the theme, 


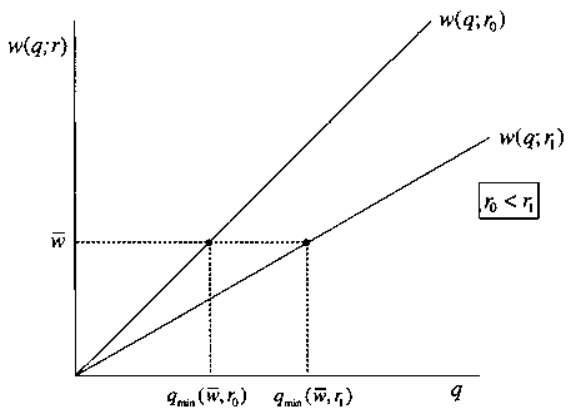

Fig. 6C.2 Interest rate and cutoff skill level

where the differential treatment relied on criteria other than simply a minimum wage, could be imagined that should result in models with similar properties.)

An Earnings Tax in the Alternative Specification

The effect of an earnings tax on wages and employment in this model would depend a little on the details of the tax. The wage-skill profile (which shows the amounts received by workers) will be shifted down by an earnings tax paid by employers. A flat percentage earnings tax, for example, would act like a proportional cut in each worker's skill level. If the minimum wage restricts what the employer is allowed to offer net of employer tax, the impact of the tax would be to raise the cutoff skill level and therefore raise the level of unemployment (fig. 6C.3). A tax paid by the workers, with a minimum expressed in terms of what the employer pays, would have a different impact. It is easy to spin out variations.

Subsidize Capital to Circumvent a Minimum Wage?

A subsidy to capital services would raise wages and reduce unemployment in this model. If the capital subsidy is financed by an earnings tax, there would be offsetting effects (and more complex effects once one recognizes the possibility of variable hours), but it is easy to imagine plausible stories that would produce a lower cutoff skill level and lower unemployment. The taxes on labor and subsidies to capital effected by the features of the tax-transfer and environmental tax-regulatory systems modeled by Rauscher would constitute instances of this phenomenon.

\section{Modeling Environmental Regulation}

I turn now to the question of the rents generated by environmental regulation. To investigate this subject, suppose capital and environmental services are uniform and that labor skills vary as in the model previously 


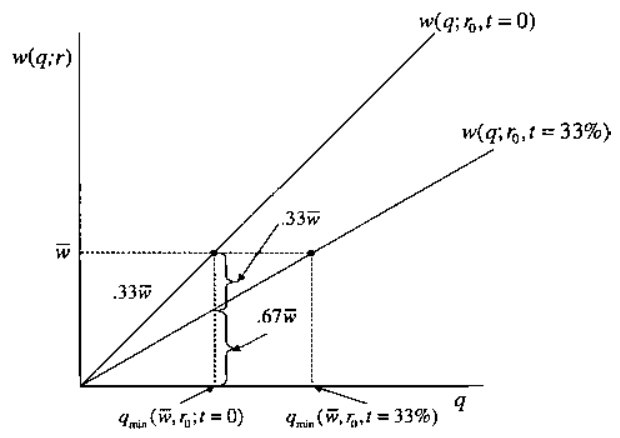

Fig. 6C.3 Effect of 33 percent earnings tax on cutoff skill

sketched out. Then, if we fix $r, \bar{w}$, and $t^{E}$ there will, in general, be an equilibrium with some level of unemployment of the relatively unskilled, some level of capital services employed, and some level of environmental quality. Any taxes in the story will also affect the equilibrium; the unemployment rate will vary with variations in these parameters of the problem. (Reminder: The capital-labor and emissions-labor ratios are basically fixed by $r$ and $t^{E}$, determining the equilibrium $\mathrm{mpl}$. Total employment varies by changes in the skill required to top the minimum wage.)

I am here a little vague about the status of the price of emissions, $t^{E}$. If emissions services are sold by their owners, as are other factors of production, they should work into the general equilibrium system just the same way as do capital and labor services. A higher price of emissions will imply a lower equilibrium wage, given the price of capital services.

Emissions are, however, owned by the government in this story. The proceeds from the sale of emissions could be spent by the government on goods, but the interesting issues arise when the emissions proceeds are used to reduce other taxes. In particular, the double dividend sorts of questions come up where the revenues are used to lower distorting taxes on labor or capital.

Rauscher studies another form of rebate of the revenue from the sale of emissions that is supposed to describe the implicit effect of environmental regulation. A regulatory arrangement can typically be described as economically equivalent to a tax-cum-revenue-rebate scheme. The implicit tax on the regulated activity is the one that would induce the regulated entity to choose the regulated level voluntarily. Since there is no actual revenue generated by this shadow tax, it must be getting handed out implicitly to someone. In Rauscher's case of central interest, the revenue handout is in proportion to a firm's use of capital services and, hence, arguably acts as an implicit subsidy to such use. As a consequence, it has the same effect on equilibrium as would an explicit use of the revenue from an explicit emissions price to finance an explicit subsidy to the use of capital. As 


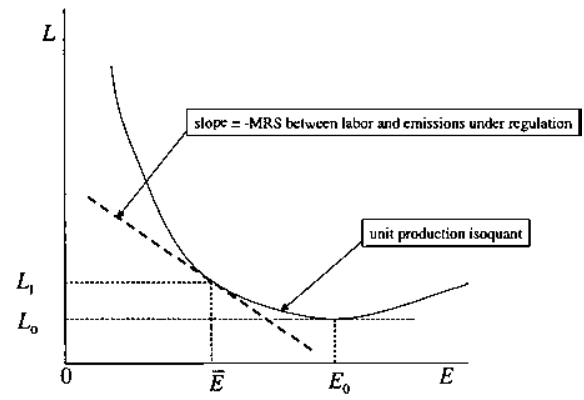

Fig. 6C.4 Regulation-constrained production

sketched out before, such a subsidy could well generate a reduction in the level of unemployment caused by a minimum wage.

What I would like to explore briefly is how the implicit revenue from an implicit tax of the type imposed by a typical regulatory program is implicitly distributed to implicit taxpayers.

\section{A Representative Regulatory Scheme}

Suppose the regulation takes the form of a prescribed maximum ratio of emissions to output. To get a feel for how this works, suppose there are just two inputs to production, labor and emissions, and forget about the minimum wage. Figure 6C.4 sketches the unit isoquant of a hypothetical production function using the two inputs. The illustrative isoquant is a little unusual in having a minimum; assuming the firm can choose its level of emissions, the upward-sloping part would never be observed. In the absence of regulation, the firm will treat emissions as free and use $E_{0}$ units of emissions per unit of output. Since labor is the only other input, under competitive conditions it must absorb the entire value of output, so the preregulation wage is $1 / L_{0}$.

Regulation is presumed to set the prescribed maximum emissions rate per unit output, identified as $\bar{E}$ in the diagram. (I am here implicitly assuming that emissions constitute a consumption externality and do not affect production; it would be easy to change this assumption, provided only that the producer remains ignorant of the feedback between emissions and production costs.) Under the regulated conditions, the wage must fall to $1 / L_{1}$. Suppose, for example, the initial wage is 1 and the new equilibrium wage is 0.75 . With full employment of labor, regulation will generate a reduction in the aggregate emissions to $\bar{E} / E_{0}$ times their unregulated level. (If the regulation changes the level of labor used, there will be a corresponding further effect on emissions.)

The production technique chosen by the firms under regulation will be the same one they would choose if, instead of the regulation, emissions 
were priced at a level that resulted in the ratio of wage to emissions price equal to the marginal rate of substitution (MRS) between labor and emissions in the regulated equilibrium, as indicated in figure 6C.4.

Suppose, to put some numbers on things, the slope in figure 6 C. 4 were $2 / 3$ (in absolute value). Then a wage of 0.45 and a price of emissions of 0.30 should do the trick. Assuming that, in general equilibrium, the seller of the emissions allowances is also a buyer of the output of the firm, this pair of prices should be an equilibrium combination-zero profits all around, and supplies equal demands. But a wage of 0.45 is obviously very different from a wage of 0.75 , the wage in the regulated equilibrium. The difference is the implicit subsidy to the input of labor (equivalently, in this case at least, a subsidy to the output of the firm) of 0.30 per unit under the regulated equilibrium.

If the government-seller of emissions rights were to use the funds to finance a subsidy to the input of labor by the firm (or equivalently, in this case, to the output of the firm), the regulated- and the priced-emissions equilibria would be economically identical. If, instead, the government were to use the funds in some other way, for example, to provide a lumpsum tax rebate to somebody, the equilibria would be different, involving a lower wage in the priced-emissions equilibrium, with all that implies.

\section{Three Factors}

If we had three factors, labor, capital, and emissions, the story should be the same in general outline. But the supply conditions of capital have a notable impact on the results. In the regulated equilibrium there are an implicit tax on emissions and implicit subsidies on the use of the two other factors. We would like to identify these components.

The net payment to the other two factors, per unit of output, will, presumably, be lower than in an unregulated equilibrium. That is, there is a penalty in terms of the productivity of the two other factors imposed by the requirement to use less emissions. If the price of capital services is fixed in the world market, the brunt of the adjustment, relative to the unregulated equilibrium, will have to be in the wage. Suppose, for example, the prices of labor and capital are 0.60 and 0.15 , respectively, whereas in the unregulated equilibrium the prices are 0.85 and 0.15 , respectively.

Suppose, again, a price of 0.30 for allowances would do the trick in inducing the firms to satisfy the emissions limit voluntarily. If the price of capital services is fixed at 0.15 , a price of labor of 0.30 would enable firms to break even at the regulated equilibrium factor proportions. But at this relative factor-price ratio between labor and capital, the firm will want to substitute toward labor input. The regulated equilibrium cannot be a priced-emissions equilibrium unless labor is subsidized at, in this case, 0.30 per unit. With that subsidy, the regulated equilibrium and the pricedemissions cum labor-subsidy equilibrium will coincide. 


\section{Rent to Be Acquired by Owners of Capital?}

What this example suggests to me, and I have not had time to track down the details or work them out for myself, is that the implicit subsidy in the regulation regime (whereby the implicit revenue is expended) depends on the supply and demand details of the factor markets (as well as the details of the regulation). It does not seem likely, however, that the implicit subsidy would be to capital in the small open economy case, simply because the supply price of capital is completely determined in that case.

\section{Is This Second-Best Framework the Right One?}

Finally, I would like to raise the issue of whether the second-best model used in this and many related analyses is, empirically, the most appropriate one. The point, which has been made forcefully by Kaplow (1996), builds on Stiglitz's (1982) insight that we forgo lump-sum taxation in order to serve distributional objectives. The distributional objectives, in turn, are served in advanced economies by an earnings-based tax-transfer system. The option of adjusting the distributional consequences of policies by altering the parameters of the tax-transfer system is always, in principle, available; the other instruments may offer the possibility of serving efficiency ends, including effects derived from interaction with the earningsbased instruments.

\section{Kaplow's Analysis}

As Rauscher's paper makes clear, the basic issues here concern the effects of imposing environmental regulation on an economy with preexisting distortions. So, for example, a typical double dividend result is that interactions with distorting taxes imply that a Pigouvian tax should be set below the marginal social damage. Kaplow's (1996) treatment of the issue assumes that the preexisting distortion is due to a graduated income tax or, more precisely, a labor earnings tax. He concludes that for what one might think of as the central case, the Pigouvian tax should just equal the marginal social damage. (This does not imply that the earnings tax itself is nondistorting, by the way.)

To sketch the story, consider a model with just one consumption good and one public good (which may be an environmental-quality measure). The third object of individual preferences is labor supply. What I have called the central case assumption is that labor supply is separable in the preferences, which means that a person's trade-off between public good and consumption is independent of the amount of labor being supplied. Cobb-Douglas preferences, equation (3), for example, have this property,

$$
U(x, h, g)=x^{\alpha} h^{1-\alpha} g^{\beta},
$$


where $x$ is the quantity of the consumption good, $h$ is hours of leisure (home use of time, i.e., time not spent at work in the labor market), and $g$ is the level of the public good.

The detail that we need to use to get Kaplow's result - that the Samuelson condition is the right criterion for determining the level of a public good - is the separability of the ranking of $(x, g)$ pairs from the amount of leisure obtained by the person. This separability is immediately apparent in the Cobb-Douglas case, since the ranking of $(x, g)$ pairs is completely determined by $x^{\alpha} g^{\beta}$. Specifically, the marginal rate of substitution between the consumption good and the public good (the dollar value of an incremental unit of the public good) is given by

$$
\frac{U_{g}(x, h, g)}{U_{x}(x, h, g)}=\left(\frac{\beta}{\alpha}\right)\left(\frac{x}{g}\right),
$$

independent of leisure consumption, $h$.

In the Kaplow story, as in the standard optimal income-tax analysis, everyone in the economy is assumed to have the same preferences, but people differ in their skills and therefore wage rates. The tax-transfer system that specifies the net tax paid by an individual as a function of that person's earnings is expressed by the function, T(earnings). Earnings are the result of supplying labor, and we model each person as having an endowment of potential labor time, for example, 24 hours per day. Then the budget constraint for a worker of skill level $q$ is given by

$$
x=w(q)(24-h)-T[w(q)(24-h)] .
$$

where, as before, the consumption good has been chosen as numeraire (so we can think of it as measured in dollars), $T$ is the net tax paid (which could be negative - the person could be obtaining a net transfer), and $w(q)$ is the wage-skill relationship already discussed.

In general, when the separability property applies, the utility function can be written as a function of two arguments: a "subutility" function of the consumption good and public good, and the amount of leisure.

$$
U(x, h, g)=u(v(x, g), h) .
$$

In the Cobb-Douglas case,

$$
\begin{gathered}
U(x, h, g)=v(x, g) h^{1-\alpha}, \\
v(x, g) \equiv x^{\alpha} g^{\beta} .
\end{gathered}
$$

Since the individual devotes whatever is left after earnings tax to the consumption of the numeraire good, there is a simple relationship between the amount earned and the subutility level achieved, given the tax system and the level of the public good: 


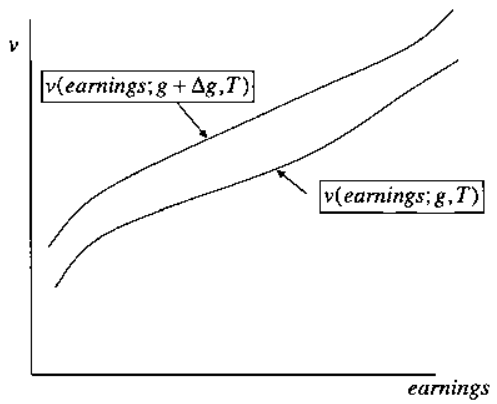

Fig. 6C.5 Earnings subutility schedules

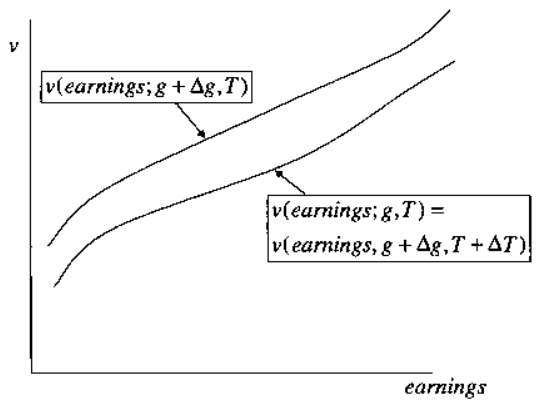

Fig. 6C.6 Fully offsetting tax system

$$
v(\text { earnings } ; g, T)=[\text { earnings }-T(\text { earnings })]^{\alpha} g^{\beta} .
$$

Now suppose the public good is measured in units of private good forgone to produce it. If in (8) we increase the level of public good by some amount, $\Delta g$, then the new $v$-earnings relationship is given by

(9) $v($ earnings; $g+\Delta g, T)=[\text { earnings }-T(\text { earnings })]^{\alpha}(g+\Delta g)^{\beta}$,

which lies above the original v-earnings relationship (fig. 6C.5).

Consider now the change in the tax system that will exactly zero out the impact of the increase in the public good (fig. 6C.6):

$$
v(\text { earnings } ; g+\Delta g, T+\Delta T)=v(\text { earnings } ; g, T) \text {. }
$$

(Again, note that $g+\Delta g$ is a scalar and $T+\Delta T$ is a function.) Specifically,

(11) $[\text { earnings }-T(\text { earnings })]^{\alpha} g^{\beta}$

$$
=[\text { earnings }-(T+\Delta T)(\text { earnings })]^{\alpha}(g+\Delta g)^{\beta} .
$$

It should be clear that equation (11) defines a new tax-transfer function, called $(T+\Delta A)$, that does the trick. (Except that it would clutter the 
notation too much, we might indicate that it depends on the specific move from $g$ to $g+\Delta g$.)

By the derivation of the tax-transfer function $T+\Delta T$, a person facing that tax-transfer system in a world with public-good level $g+\Delta g$ would have exactly the same v-earnings alternatives as a person facing taxtransfer system $T$ in a world with public-good level $g$. So each person will make the same labor-supply choice in both cases. Suppose the amount of tax raised by the new system is more than enough to finance the increment to the public good. Then we know it is possible to make the change and have some money left over to make a Pareto improvement in the taxtransfer system. So we can always undertake a change that passes the Samuelson test, combined with a change in the earnings tax, so as to make everyone better off.

Notice that, as I have mentioned, the earning tax generates distortions before and after the change. The marginal tax rate before the change, as a function of earnings, is $T^{\prime}$ (earnings); the marginal tax-rate schedule after the change is $(T+\Delta T)^{\prime}$ (earnings). The original tax-transfer function is whatever it is and the new one is related to it by equation (10).

Long Preamble, Short Conclusion

With earnings- or income-based tax-transfer systems as elaborate as those of most developed countries, does it make sense to attempt to influence the level of unemployment by manipulating environmental policy?

\section{References}

Kaplow, Louis. 1996. The optimal supply of public goods and the distortionary cost of taxation. National Tax Journal 49/(4): 513-33.

Stiglitz, Joseph E. 1982. Self-selection and Pareto efficient taxation. Journal of Public Economics 17:213-40. 
